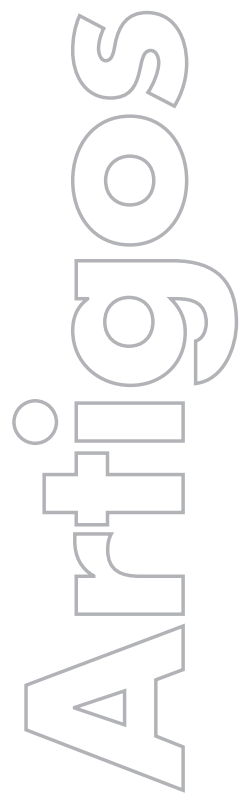

revista

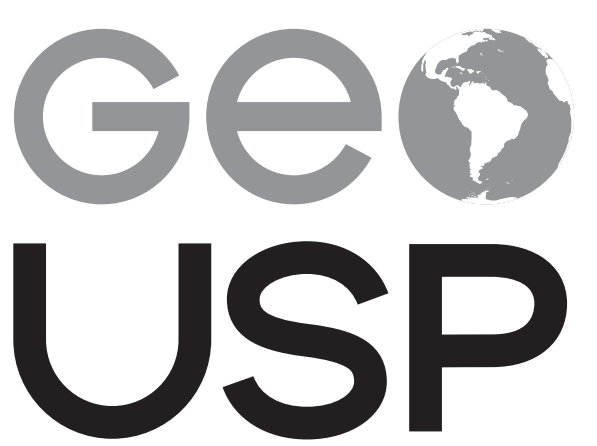

espaço e tempo

Volume $22 \cdot n^{\circ} 3$ (2018)

ISSN 2179-0892

\section{Cinco visões sobre a terra na geofilosofia de Nietzsche}

\author{
David Emanuel Madeira Davim \\ Unicamp
}

Eduardo José Marandola Junior

Unicamp

p. $729-746$

Como citar este artigo:

DAVIM, D. E. M, MARANDOLA JUNIOR, E. J. Cinco visões sobre a terra na geofilosofia de Nietzsche. Geousp

- Espaço e Tempo (Online), v. 22, n. 3, p. 729-746, dez. 2018. ISSN 2179-0892

Disponivel em: <https://www.revistas.usp.br/geousp/article/view/141353>. doi: http://dx.doi.org/10.11606/issn.21790892.geousp.2018.141353.

\section{(c) $\underset{\mathrm{BY}}{\mathrm{BY}}(\mathrm{NC}$}

Este artigo está licenciado sob a Creative Commons Attribution 4.0 License. 


\title{
Cinco visões sobre a terra na geofilosofia de Nietzsche
}

\section{Resumo}

Nietzsche é reconhecidamente um pensador de espírito iconoclasta, assim como um demolidor de ídolos, visões de mundo e fundamentos morais. Mas há outro movimento igualmente valioso em sua filosofia que parece ter ficado em segundo plano. Tal movimento nos convoca a compreendê-lo também como um pensador edificante e propositivo, trazendo em seus escritos bases para pensar uma nova Ciência e Filosofia, afirmando outras realidades, novos valores, assim como perspectivas de vida e mundo. Por esse caminho, Nietzsche seria fundamental a uma hermenêutica que teria forte reverberação na geografia fenomenológica contemporânea. Em nossa interpretação, a filosofia nietzschiana guarda uma cosmologia surpreendente e perturbadora. Uma compreensão e visão de mundo particular que, se desdobrada com atenção, é capaz de dispor uma postura hermenêutica sobre a existência, bem como uma geofilosofia interpretativa. É sobre os alicerces dessa possível cosmologia e geofilosofia nietzschiana que se debruça nossa investigação. Inicialmente, exploramos a multiplicidade da terra como um dos termos basilares dessa cosmologia. A partir dela, nos permitimos pensar outras reverberações geográficas e filosóficas de semelhante valor, por exemplo, cosmo e mundo.

Palavras-chave: Hermenêutica nietzschiana. Terra. Geofilosofia. Epistemologia da geografia. Filosofia da geografia.

\section{Five visions on earth in Nietzsche's Geophylosophy}

\begin{abstract}
Nietzsche is recognized as an iconoclastic spirit thinker as well as a demolisher of idols, worldviews and moral foundations. But there is also another valuable feature in his philosophy that seems to be of little importance. This characteristic leads us to understand Nietzsche also as an uplifting and propositive thinker, who brings in his writings, bases for thinking a new Science and Philosophy, affirming other realities, new values, as well as perspectives of life and world. By this way, Nietzsche would be fundamental to a hermeneutic with strong reverberation in
\end{abstract}


the contemporary phenomenology geography. In our interpretation, Nietzsche's philosophy carries with it an astonishing and disturbing cosmology. A particular understanding and worldview that is capable of disposing a hermeneutical posture on existence, as well as an interpretive geophilosophy. It is on the basis of this Nietzschean cosmology and geophilosophy that our investigation turns. Our effort is to excavate the multiplicity of the earth, as one of the basic terms of this cosmology. From it we will allow ourselves to think of other geographical and philosophical reverberations of similar value, like the cosmos and the world.

Keywords: Nietzschean hermeneutics. Earth. Geophilosophy. Epistemology of geography. Philosophy of geography.

\section{A terra improferível}

Terra. Talvez um termo dos mais múltiplos e assiduamente explorados em diversas línguas, modos de expressão e formas de conhecimento. Certamente um termo dos mais caros às Ciências. Uma palavra que tanto é componente, quanto se faz contida no sentido de geografia (referente ao grego $\gamma \widetilde{\eta}-g \bar{e}$ - geo - terra) e, espantosamente, tão pouco utilizada. Subutilizada talvez seja um adjetivo mais adequado.

Algo semelhante Holzer (2012) anotou sobre o conceito de "mundo", referindo-se à sua posição secundária, sendo resgatado apenas a partir dos anos 1990, já no contexto dos estudos sobre mundialização/globalização. Mesmo assim, o autor salienta sua pouca problematização, entre os geógrafos, como conceito fundamental ao geográfico.

Neste uso hodierno, assim como no caso de mundo, terra não aparece como conceito geográfico, o que é igualmente curioso. Pattison (1977), em seu resgate daquilo que chama de quatro tradições geográficas, desde os gregos, relaciona duas delas à ideia de terra: geografia como ciência da terra, que remontaria a Aristóteles, e geografia como estudo das relações homem-terra, que remontaria a Hipócrates. As outras duas fariam referência à superfície terrestre, mas conceituando-a de outra forma: geografia como diferenciação de áreas (ligada a Heródoto) e geografia como ciência espacial (derivada de Ptolomeu).

Nota-se, nesta proposição de Pattison (1977), talvez o fundamento deste esquecimento da terra: voltando-se para categorias construídas para dar legibilidade ao espaço geográfico, como espaço, região, paisagem ou território, tais conceitos passam a expressar o sentido das relações referentes ao geográfico, deixando a terra como um fundo, quase que uma matriz, em seu sentido de natureza não humana (precedente).

Essa leitura pode ser reforçada ao acompanharmos as formulações dos geógrafos europeus das primeiras décadas da geografia científica. No entanto, parecem conviver na mesma época dois movimentos: o de manutenção do interesse nos termos "brutos" de tal relação, como vemos em muitos grandes trabalhos, e a adoção de conceitos que expressem a natureza desta relação como sendo a do sentido da terra como morada humana, ou seja, assumindo como geográfico o resultado dessa relação. 
No primeiro caso, temos os clássicos homônimos L'homme et la terre, de Elisée Reclus (1830-1905) (Réclus, 1905), e o pequeno clássico da geografia fenomenológica, de Éric Dardel (1889-1967), (Dardel, 2011). A força de tal perspectiva é tamanha que vemos muitos livros se repetirem nessa formulação, como livros posteriores que aparecem no Brasil nos anos 1960, como a grande coletânea brasileira dirigida por Aroldo de Azevedo, Brasil: a terra e o homem (em dois volumes) (Azevedo, 1967), e o clássico de Manuel Correia de Andrade: A terra e o homem do Nordeste (Andrade, 1963).

No segundo caso, além do pioneirismo de Humboldt sobre o cosmo, que era uma descrição física do mundo, mas em uma compreensão que continha como princípio a unidade, incluindo a apreciação estética (Vitte; Silveira, 2010; Silveira; Vitte, 2010), o próprio conceito de meio, fundamental na geografia lablachiana (Buttimer, 1971; Berdoulay, 2017) ou mais recentemente de ecúmeno, proposto por Augustin Berque (2009).

Embora estes autores, desde Réclus, Dardel, Humboldt, La Blache e outros, tenham utilizado terra como conceito, eles o fizeram a partir da filosofia, sem o esforço explícito de tornar a terra um conceito propriamente geográfico. Ele aparece como fundo, como conceito certamente originário do sentido geográfico, mas que se desvanece no momento seguinte a partir da construção ou adoção de conceitos que expressão o geográfico, já como resultado da relação homem-terra: cosmos, ecúmeno, meio, paisagem, território, região, espaço.

Este esquecimento da terra, parece acentuar-se com o esforço neopositivista e a ênfase no espaço assumindo um sentido mais instrumental, retomando em grande medida os princípios ptolomaicos ligado à compreensão da superfície terrestre como espaço geométrico (Oliver, 1979) ou por transformá-la em recurso, via problemática ambiental (Haggett, 1975). Isso se manifesta na compreensão categorial a partir do conceito de espaço, que hierarquiza paisagem, lugar, território e região que, a partir dali, serão compreendidas como categorias (Harvey, 1969). Este tratamento da terra não é rompido pelas abordagens críticas que se difundem a partir dos anos 1970, embora dotem tais categorias de um sentido ontologicamente social (Harvey, 1973; Santos, 1978).

No entanto, o termo parece ter recebido uma retomada a partir dos geógrafos humanistas, talvez motivada pelo resgate da obra de Dardel. Jean-Marc Besse publica Ver a terra: seis ensaios sobre paisagem e geografia (Besse, 2006); Paul Claval publica Terra dos homens: a geografia (Claval, 2010), um livro destinado para o público geral com forte tom humanista-cultural; por fim, o próprio Berque publicou, recentemente, Poétique de la terre: histoire naturelle et histoire humaine, essai de mésologie (Berque, 2014). Todos fazem, de um jeito ou de outro, menção a Dardel, estabelecendo por caminhos diferentes, uma retomada da terra, embora não a tomem, diretamente, como conceito geográfico.

Este artigo pode ser colocado nesta senda, como desdobramento do esforço pioneiro de Dardel e de sua retomada recente, sobretudo no que tange às contribuições da fenomenologia para a Geografia. No entanto, nos esforçaremos aqui em tratar o termo terra como um potencial sentido geográfico, capaz de amparar proposições e conceituações, em busca de um dos fundamentos filosóficos que deram sustentação, ao menos parcial, ao esforço dardeliano. Trata-se, a princípio de um empreendimento ontológico que beberá particularmente das lições do pensador Friedrich W. Nietzsche, filósofo caro para o contexto contemporâneo, assim como para o debate 
sobre a modernidade (Giacóia Jr., 2000). Em nossa avaliação e segundo referências como Feitosa (2011), Günzel (2003), Shapiro (2010, 2013) e Wainwright (2010), Nietzsche foi um pensador que se valeu de elementos de caráter geográfico para conduzir sua filosofia. Entre esses elementos, os termos e noções mais mobilizados em seus escritos estão a terra e o mundo, sentidos fundamentais para a sustentação do que entendemos por geofilosofia nietzschiana.

Para Günzel (2003), a geofilosofia nietzschiana nasceria de uma preocupação filosófica primordial, isto é: pôr em questão a incondicionalidade dos valores metafísicos em detrimento de um desvio de retorno, ou resgate da virtude e da tarefa filosófica para a terra, a superfície em que, originariamente, se dá a existência, a dimensão do concreto, do efetivo e fático, o dito mundo-da-vida. Seu passo a diante se comprometeria em fazer uso de termos geográficos (fortemente relacionados com o sentido de paisagem) para sustentar ideias e fazer do instante experienciado e vivido a circunstância deste filosofar. Para filósofos como Paulo D’ lorio (2014), Frédéric Gros (2010), Graham Parkes (2005) e Gary Shapiro (2010, 2013), Nietzsche foi um pensador que fez de suas experiências vividas (viagens, passeios, estados e sintomas corpóreos, condições de saúde e relações interpessoais) matéria-prima para criar pensamentos e filosofemas. Na visão de Shapiro (2013), tal conjunto variado de experiências faria desabrochar na filosofia de Nietzsche uma espécie de geoestética (arte, poética), assim como uma geologia e geografia do pensamento, atenta, imanentemente, às estratigrafias erigidas pelos grandes acontecimentos sobre a terra.

Como nos argumentos de Günzel (2003), a proposta de Nietzsche conduz a Filosofia ao campo da Geografia, trazendo a virtude do pensar para a tarefa de compreender a efetividade de um mundo fático, de uma existência que acontece sobre a concretude da terra. Esse é o sentido de geofilosofia que exploraremos na maturidade da obra nietzschiana. Por meio dela nos dedicaremos a desdobrar uma pluralidade de sentidos, termos e noções que acreditamos ter valor para o pensamento geográfico. Terra, portanto será o primordial entre os termos geofilosóficos de Nietzsche, sendo que, a partir dela, desdobraremos outros dois não menos importantes: mundo e cosmo. A partir de uma inserção genealógica e uma interpretação (hermenêutica) perspectivista (que se vale da multiplicidade), nossa intenção é construir um caminho para conduzir (em breve) os múltiplos sentidos destes termos nietzschianos ao centro dos debates conceituais e metodológicos do pensamento geográfico.

No que compete a este artigo, o desafio, é dar conta, ao máximo, da obra nietzschiana para assim adentrar nas multiplicidades e profundidades de como o pensador trata determinados temas. Em específico, traremos aqui da amplitude do termo terra (erden) palavra que Nietzsche requisita em toda a sua obra, sendo que, em cada uma delas, a desdobra em uma multiplicidade de sentidos que se distinguem e ao mesmo tempo se complementam. Ao todo, exploramos neste escrito cinco visões (visadas, perspectivas) sobre a terra, apanhadas em diferentes obras do autor (e em diferentes fases) considerando também a interpretação de alguns de seus mais respeitados estudiosos e comentadores, São elas: (1) terra como mundo-aquém, (2) terra como cosmo, (3) terra como subtaneidade, (4) terra como topos-poético e (5) terra como horizonte humano. Cinco perspectivas e sentidos sobre o mesmo termo ou palavra. Uma luta entre pontos de vista que edificam a terra como um modo de pensar geofilosófico que cremos ter muito a contribuir para o conhecimento em geral, sobretudo para o pensamento geográfico e seus debates epistemológicos. 


\section{Terra como mundo-aquém}

Uma das primeiras sentenças de Nietzsche (1992) sobre terra não trouxe a palavra em sua condição radical (terra), mas em uma de suas derivações, desterra (do verbo desterrar), mas que, ainda assim, traduz muito bem essa ideia de terra como mundo-aquém (Barrenechea, 2009, p. 34), ou seja, terra como um mundo que nos é próximo, no qual estamos enraizados, sobre o qual existimos em vida (imanente e efetivamente), terra como realidade concreta, física e fática, ou o aqui e agora, como nas palavras de Parkes (2005). Para Günzel (2003), esse sentido nietzschiano de terra se projetou em sua filosofia como enunciado crítico à metafísica, assim como ato de pôr em questão as bases platônicas de um além-mundo transcendente e ideal. Na Geografia, tal perspectiva imanente de terra também se faz presente na obra capital de Eric Dardel (2011), que a entende como realidade concreta, de natureza imanente, que se apresenta ao homem pela sensibilidade.

No segundo livro de Humano, demasiado humano, assim como em Aurora, Nietzsche (2004, 2012b) trata desse sentido de terra como o equivalente ao contrário ao céu, o plano que a tradição depreciou como mundo corrompido e imperfeito da aparência (Randles, 1999). Nesta perspectiva, a terra nietzschiana seria a dimensão que nos é mais íntima, o mundo das coisas que nos são vizinhas e que a moral ascética do platonismo desprezou e condenou aos valores de horrenda morada e campo do infortúnio (Nietzsche, 2004, p. 46).

Se valendo do ideal de desterro da vida como caminho para o céu, Nietzsche (2009a, 2012b) trouxe à tona o problema da moral triunfante como ressentimento sobre a vida e os afetos. Este condena a terra como a responsável pela impossibilidade do saber e da paz, já que todos os seus objetos estão à mercê do devir. Tal natureza imponderável doa incertezas à humanidade, sendo estas o véu do prejuízo para seus planos e intenções. Está posto, portanto, a genealogia do desprezo terrestre. Cabe, portanto, a humanidade renunciar aos aliciamentos da terra, que reverberam diretamente sobre os sintomas dos corpos, e se voltar para o que de fato existe como bem, belo e verdadeiro

Considerando a herança desse desprezo terrestre, Nietzsche (2011b), no prólogo de Assim falou Zaratustra, expressa uma de suas sentenças de caráter mais convocatório para a suspensão da ascese moral:

[...] Eu vos imploro, irmãos, permaneceis fiéis à terra e não acreditais nos que vos falam de esperanças supra-terrenas! [...]. Uma vez a ofensa a Deus era a maior das ofensas, mas Deus morreu, e com isso morreram também os ofensores. Ofender a terra é agora o que há de mais terrível [...]. Uma vez a alma olhava com desprezo para o corpo [...]. Assim pensava ela escapar ao corpo e à terra (Nietzsche, 2011 b, p. 14, grifos nossos).

Suspender a moral ascética e retornar à terra, seria, portanto, dar à Filosofia, assim como a todo o conhecimento humano, um novo terreno analítico-reflexivo, a possibilidade de ultrapassar a tradição em seus limites suprassensíveis. Retornar à terra seria resgatar a extraviada virtude do pensamento para o campo da vida, da concretude, dos acontecimentos e para a dimensão fática da existência humana. Afinal, a vida seria aquilo que de fato vale a pena ser pensado e que deve ser pensado pelo filósofo ou cientista, sendo a metafísica um aborto, esforço desperdiçado, uma ilusão, uma perda de tempo com coisas que não existem, como crer em fantasmagorias (Nietzsche, 2011a, 2011b). 


\section{Terra como cosmo}

A terra nietzschiana também implica a ideia de totalidade que se remete a uma concepção de mundo. O termo mundo também é muito usado e de modo variado nos escritos de Nietzsche; em algumas passagens, é possível confundi-lo com terra, como imanência, este mundo, mundo-aquém, plano inferior e desprezado pela tradição.A terra como "este mundo" também comparece na filosofia de Nietzsche como refutação da dicotomia platônica de cisão entre dois planos: mundo das coisas e mundo das ideias. Não se trata de mencioná-lo mais como plano aparente, pois, sob essa nomenclatura, a terra ainda seria, por oposição, a pressuposta possibilidade de outro mundo, de caráter verdadeiro e essencial (Barrenechea, 2009). Nesse sentido, para Nietzsche (201la, 2011b, 2012b), só há um mundo possível, a terra, o ente em sua totalidade, o mundo físico, efetivo, que poderíamos chamar de universo, mas que alguns estudiosos e comentadores de Nietzsche preferem chamar de cosmo (Marton, 2010; Müller-Lauter, 2009).

Para a filósofa Scarlett Marton (2011), a concepção greco-arcaica de cosmo em Nietzsche cumpre uma disposição edificante pouco explorada em detrimento de sua famosa genealogia. Para a autora, Nietzsche entende a totalidade efetiva do mundo como um corpo contínuo, eterno e finito, constituído por uma contiguidade múltipla de outros corpos, todos eles dotados de uma diversidade de necessidades próprias, contraditórias e antagônicas.

Por ser finito, o cosmo nietzschiano preserva sua condição corpórea sempre como a mesma, sem perdas, sem acréscimo, possibilitando que suas combinações e fatos tenham um limite, o que proporciona repetições constantes, base para a sua perspectiva de eterno retorno como devir cósmico. $\bigcirc$ caráter deste cosmo é o caos eterno, o que corresponde a uma falta de ordem, lei, razão, divindade, moralidade, princípio, finalidade ou causalidade. Esse mundo seria marcado por uma dinâmica repetitiva, mutante e conflituosa entre seus componentes, caráter que faz dele um combate incessante entre forças que, simultaneamente, se enfrentam, resistem, obedecem e se hierarquizam a todo instante (Marton, 2010).

Para essa multiplicidade, que constituem o mundo como totalidade, Marton (2010) associou o conceito nietzschiano de vontade de potência, que é o em-si do mundo e da terra (Nietzsche, 2012b), o caráter fundamental (Heidegger, 2010) e o quantum de efetivação de todas as suas coisas (Marton, 2010). No mundo de Nietzsche (2011a), todo corpo ou coisa constituinte está viva, desde a célula mais complexa até a partícula mineral mais simples. A vontade de potência, portanto é a dinâmica, assim como a própria concretude do corpo cósmico. Ela não é a causa, mas consequência de si mesma, de sua própria condição conflituosa, perspectiva que descarta o seu entendimento como substância, ou princípio metafísico incondicionado (Müller-Lauter, 2009; Stegmaier, 2013).

A natureza conflituosa do cosmo nietzschiano é o que mobiliza o devir da efetividade, tanto em um movimento de destruição, quando de reconstituição própria. É este devir, também compreendido como um vir-a-ser outro (Nietzsche, 2012a), ou vir-a-ser mais (Marton, 2010), que possibilita a contingência característica da cosmologia de Nietzsche, a saber, a mudança eterna do mundo, a condição indeterminável e imponderável do real que não permite estabelecer verdades últimas, universais e absolutas.

O sentido de terra como cosmo também se faz presente, em particular intensidade e caráter, na obra intitulada $O$ homem e a terra, do geógrafo francês Eric Dardel. A terra, segundo Dardel (2011), além de uma realidade concreta e material, está intimamente relacionada com homem 
em seu modo de existência, formando com ele uma duplicidade em constante luta. Em sua visão, a Terra, em suas potências (forças), afeta e provoca as vontades do homem por meio de recusas (obstáculos) e aberturas (possibilidades). Deste modo, o homem interpelado tende a responder não apenas em ação, que desafia e transforma a natureza, mas também como linguagem. Para o geógrafo, a Terra tem uma virtude convocatória que, por meio de seus apelos materiais, conduz o homem a imaginar, traduzir e decifrar suas feições e ações, desdobrando assim um conjunto de sentidos geográficos capazes de constituir um verdadeiro vocabulário sobre ela. A nosso ver, as forças em luta, ou o jogo de estímulos e respostas entre homem e terra na obra de Dardel revela uma aproximação com o "campo de forças" correspondente à cosmologia nietzschiana.

\section{Terra como subtaneidade}

A terra de Nietzsche (201lb) é da mesma carne de seu cosmo finito, eterno, caótico e conflituoso. Porém, há uma particularidade que, nesse caso, não dicotomiza as duas dimensões, mas estabelece uma propriedade que se faz evidente por questão de escala. Do ponto de vista do conhecimento humano, não se pode conceber a totalidade desse cosmo, aqui tratado, via facticidade desse mundo-aquém. A totalidade macro do cosmo, mesmo que finita, não é abarcável pela dimensão micro do corpo, cabendo a este último a alçada imediata de sua própria condição sensível, isto é, a extensão da sua sensibilidade: até onde se ouve, até onde se vê, até onde se toca, até onde se cheira (entre outros sentidos) na circunstância do vivido (Fogel, 2011; Barrenechea, 2009).

Portanto, nesta perspectiva, a terra é uma subtaneidade (Plötzlichkeit - Plötzlich - rápido, repentino, súbito) cósmica, um mundo para o nosso alcance sensível, que nos aparece de forma rápida e repentinamente, mediante o instante vivido, o acontecimento presenciado e que se abre circunstancialmente à experiência (Nietzsche, 2011 a).

Segundo Nietzsche (201la), a terra também é corpo e vida. Porém, a filosofia ascética, assim como a moral ressentida, desesperou do corpo em detrimento da razão como único acesso ao além-mundo de suposta verdade, bondade e perfeição (Nietzsche, $2011 \mathrm{la}, 2011 \mathrm{~b}$, 2012b). Desesperada do corpo a Filosofia afastou-se automaticamente da terra. Tal condição de degenerescência deu a Nietzsche (201la) o esforço e ambição de resgatar a terra e o corpo para o pensamento, como modo mais originário e eficaz de pensar fazer ciência e assim conhecer e compreender a efetividade do mundo. Desse modo, Nietzsche nos convoca a permanecer em fidelidade à terra e recuperar a esperança na vida e no corpo. Para o filósofo, o homem deve tornar-se um escutador de entranhas, ou seja, deve voltar suas atenções sobre os sintomas do corpo, pois este é a correspondência mais imediata da vontade de potência, o Si-mesmo que caracteriza fundamentalmente todo o ente e a totalidade do cosmo.

Para Barrenechea (2009), assim como para Nietzsche (201la), corpo e mente não constituem uma dicotomia, pois são o mesmo, o que faz do corpo um ente capaz de pensar via os próprios sintomas, sentidos e afetos: pensar-sentindo. $\bigcirc$ corpo é a razão maior de nossa condição humana e sendo ele a correspondência direta ao cosmo e à terra. Seu pensamento é o mais potente esclarecimento e meio de compreensão sobre a efetividade. São as condições corporais, ou os estados de saúde, como destaca Barrenechea, que nos possibilitam aquilo que Nietzsche (2008) nomeou de geografia médica ou farmacológica sobre a terra, sendo esta compreendida como totalidade mundana, um conjunto de estações corporais (de saúde). 
Ao lado desse tratamento dos espíritos, a humanidade deve procurar, no tocante ao corpo, mediante uma geografia médica, descobrir quais degenerações e enfermidades cada região da Terra ocasiona e, inversamente, quais fatores curativos oferece; então, gradualmente, povos, familias e indivíduos devem ser transplantados, de forma demorada e contínua, até que sejam dominadas as doenças físicas hereditárias. A Terra inteira será, enfim, um conjunto de estações de saúde (Nietzsche, 2008, p. 185, grifos nossos).

Desta feita, o pensar terreno de Nietzsche, traria a escala do corpo como base geofilosófica mais à mão de seu pensamento. Para Shapiro (2013), essa perspectiva da terra como imanência, ou súbita dimensão sensível da experiência, foi a proposição filosófica mais requisitada de Nietzsche pela fenomenologia, tendo Gaston Bachelard (2011) um dos autores de referência. No entanto, é provável, que Martin Heidegger seja o principal, entre os célebres fenomenólogos, a se valer de elementos da visão de terra nietzschiana, tendo Jeff Malpas (2008) como um dos poucos estudiosos a sinalizar tal herança.

Para Malpas (2008), a terra heideggeriana seria o solo ou o fundamento para o ato poético sobre a existência. Tal dimensão traz consigo o sentido de facticidade, plano concreto das coisas, dos acontecimentos e da vida ao qual Heidegger (2009) atribui também a ideia de o fundo escuro. Essa influência, que traz em si elementos da subtaneidade nietzschiana, tocaria a Geografia via o trabalho de Eric Dardel (Davim, 2015). Para Dardel (2011), a terra também traz consigo as bases para o lugar, a situação, meio de realização para sua geograficidade, isto é, o ato humano de interpretar os apelos (ou a voz) da terra.

Mesmo que a terra como dimensão imanente da experiência seja um elemento fenomenológico importante na filosofia de Nietzsche, reconhecemos que a próxima visão trabalhada tem muito mais a esclarecer sobre essa relação, assim como sobre a proximidade entre Nietzsche e Heidegger.

\section{Terra como topos-poético}

Como já explorado, Nietzsche (2009a, 201la, 2011b, 2012b, 2014) se manteve combativo à tradição por inúmeras frentes: contra a moral ascética, contra as dualidades metafísicas, contra os imperativos categóricos a priori, além de manter-se contra ao desprezo sobre o imanente, entre outras. Um de seus mais famosos e vigorosos enfrentamentos está também no ataque ao antropocentrismo, assim com a antropogênese do pensamento. Para o filósofo, a exaltação do humano como animal racional, ente superior, sujeito hierárquico do conhecimento e imagem do divino é mais um sintoma do nilismo europeu, isto é, a mesma enfermidade que, do contexto clássico ao moderno, devastou a cultura ocidental.

Para Nietzsche (201la, 201lb, 2012b, 2014), o homem é um corpo entre os corpos, um animal entre os animais. Seu desespero diante a terra e seu uso recorrente da lógica, assim como da razão, o fez, na verdade, o mais ameaçado entre os seres. No entanto, Nietzsche (2009a, 201la, 201lb) reconhece no homem uma particularidade mediante os outros entes do cosmo, a saber, o homem é o animal moral e avaliador (valorador), isto é, aquele que, ao pensar-sentindo, julga, doa qualidade, cor, peso e valor à terra. 
Na visão de Nietzsche (201la), valorar a terra não é um problema para o homem e sim o modo como essa valoração é desempenhada. Para o filósofo, a limitação está no uso incondicional e sistemático da consciência, elencada pelo humanismo convencional como único meio aceitável para pensar, conhecer e existir. Na perspectiva de Nietzsche, a consciência não passa de um instinto do humano, o mais frágil entre eles, seu instrumento mais carente de aprimoramento. Isso se dá, pois, para o filósofo, a consciência não sabe lidar com a multiplicidade de elementos que constituem a vida e a totalidade, limitando-se em excluir, de sua capacidade analítica, as incoerências, inconsistências e contradições, peças que não se encaixam em seu modo burocrático, objetivo e lógico de apreender o mundo.

Como já explorado, na segunda visão sobre terra, a filosofia nietzschiana traz em si uma compreensão de mundo como multiplicidade conflituosa de corpos, forças, ou vontades de potência. $\bigcirc$ corpo humano, seria o ente eficaz em apreender e compreender, por meio de um pensar-sentindo, essa multiplicidade cósmica. Todo corpo é perpassado pelos inúmeros impulsos advindos do próprio mundo. A corporeidade tanto recepciona, quanto responde a estes impulsos como uma multiplicidade de afetos, impressões, sensações e sentimentos, que lutam entre si no interior de cada corpo (Nietzsche, $201 \mathrm{la}$, 201lb).

Segundo Nietzsche (201la), essa multiplicidade conflituosa de afetos corporalmente apreendida, permanece íntegra, em primeiro lugar, no campo do inconsciente, pois quando emergem à consciência sofrem uma espécie de apaziguamento e seleção rigorosa. A consciência seleciona só os afetos e sensações que correspondem as suas exigências lógicas, ou seja, aquelas que se adequam melhor à sua imagem, aos modelos e leis racionais, o que acaba por desprezar qualquer elemento de diferenciação, o que é, em grande parte, a riqueza factual e fenomênica que se faz manifesta no mundo. Mas as limitações da consciência não fazem dela algo a ser amputado da natureza humana, muito pelo contrário. Para Nietzsche (201la), a consciência deve cumprir um papel importante em sua proposta de conhecimento, pois esta deve servir ao corpo como um entre os instrumentos valorativos.

Para superar essa limitação consciente da apreensão mundana, Nietzsche (2011a, 201lb) nos propõe o corpo como caminho mais potente para a valoração. Como já explorado na terceira visão, retornar ao corpo é retornar à terra e à vida, é se abrir para uma compreensão íntima e originária sobre o mundo. $O$ corpo é esse ente que na subtaneidade sensível e senciente é capaz de auscultar e apreender o cosmo em sua riqueza e multiplicidade. $O$ corpo é visitado e afetado por uma multiplicidade de estímulos (forças) que o levam a pensar. Essa afetação pelo mundo se manifesta no corpo como um estado estético-poético, que também é sensível e psíquico e que Nietzsche denomina embriaguez.

Se cultivada com sincero interesse e curiosidade, essa embriaguez pode apanhar a multiplicidade do real e servir à arte polissêmica de interpretação, resultando em uma multiplicidade de perspectivas e valores sobre os fenômenos. Uma interpretação capaz de traduzir poeticamente o caráter das vontades atuantes, que se dá de forma súbita e circunstancial, proporcionando diferentes convicções sobre a realidade. Os resultados desse modo de conhecer obedecem à dinâmica caótica e mutante do mundo, pois nunca se estabilizam ou cristalizam, tão pouco se resumem a uma unidade ou universalidade. Seu caráter é a eterna mudança o que nos obriga, constantemente, a renovar nossos esforços interpretativos sobre a terra, refundando, a cada experiência, novas palavras, valores, nomes e conceitos. Um desafio, assim como uma demanda imensa e interminável para o saber. 
Segundo Machado (2006), a proposta nietzschiana de conhecimento já fora gestada desde elaboração de $O$ nascimento da tragédia, em que se discute o sentido de arte. Para Heidegger (2010), a arte em Nietzsche advém de uma perspectiva grega muito distante do sentido estético do mundo moderno. Nietzsche enxerga a arte como poíesis, ou seja, um fazer, criar, ação produtiva que irrompe da vida, do corpo embriagado e interpelado pelos estímulos da terra. Ao irromper da relação corpo-terra, a arte, como vontade de potência, se concretiza em acontecimento poético (palavra, construção, imagem, cena, gesto, música). Para Marton (2010) e Machado (2006), a arte trágica de Nietzsche é um ato valorativo de interpretação perspectivista, a expressão múltipla do verdadeiro que contrapõe o niilismo, uma afirmação da vida, decifração polissêmica que emerge da diferença. A associação entre valoração e interpretação na filosofia de Nietzsche não se limita à leitura de Heidegger, Marton e Machado. Tal analogia teve fortes confirmações e contribuições de teóricos e comentadores como Granier, Stegmaier e Barrenechea.

No caso de Barrenechea (2009), Nietzsche é entendido como aquele que nos convoca a tornarmo-nos filósofos toupeiras, ou seja, aquele que cria em terra e pelo corpo, que escava, desce e penetra, em suas profundezas, nos refúgios recônditos do mundo e do homem. A associação da filosofia com a imagem da toupeira nos conduz à ideia de Gaia Ciência como arado, ou seja, um saber que dimensiona e explora a terra como uma relha (de arado), o instrumento que penetra e revira a terra fazendo emergir sua fecundidade adormecida, um novo e vigoroso solo fundamental para a criação, renovação ou transvaloração de todos os valores caducos, cansados e improfícuos da tradição filosófica.

Para Barrenechea (2009), o corpo é essa relha de arado, um guia e fio condutor para aquilo que o estudioso reconhece como um método nietzschiano de interpretação. Desse modo, o trabalho do interprete da terra é assemelhado ao exercício de um arqueólogo, genealogista, médico ou terapeuta, que, em uma espécie de anamnese, interroga e avalia os sintomas corpóreos (estados de saúde) e deles identifica afetos que se desdobram em ideias e que, por sua vez, se traduzem em sentidos e nomeações.

Jean Granier (2009) é mais um estudioso e comentador de Nietzsche que evidencia no filósofo a existência de um método hermenêutico que considera a terra lugar ou topos para tal ação. Assim como na segunda visão de terra, na qual se destaca uma cosmologia, Granier sinaliza na filosofia de Nietzsche um sentido de caos como caráter fundamental do mundo e das coisas como de fato são (caos como coisa-em-si). $O$ caos do mundo, por sua vez, subsiste como texto originário a ser lido e interpretado, porém, não pelo sujeito clássico do conhecimento (eu penso, logo sou), mas pelo Eu-mesmo do humano, ou o Si-mesmo como corpo e vontade de potência, ideia intensamente tratada por Nietzsche (201lb) em Assim falou Zaratustra. Granier, portanto, além de confirmar aspectos cosmológicos já explorados, traz também consigo a perspectiva de corpo como "razão maior" no ato interpretativo. Em seu modo propositivo, o corpo é o sujeito como tal, a sabedoria geral de todo organismo.

Na visão de Granier (2009), o intermédio entre terra e corpo são os acontecimentos psíquicos, que fundem em uma só estas duas dimensões do existir: a natureza interior e exterior. Essa relação, no entanto, não pode ser vista como um fundamento homogêneo do conhecimento, pois a condição de caos faz do mundo uma multiplicidade heterogênea de tais 
relações. É justamente nessas multiplicidades de inter-relações (entre terra e humano) que Granier aponta a ideia de centros (polos) interpretativos, isto é, a situação (sítio) ou lugar onde o humano, como animal estimador (avaliador) por excelência, pode desempenhar, diante dos seus acontecimentos psíquicos, uma espécie de filologia hermenêutica em que concebe o mundo como múltipla expressão textual de valores, que em seguida são desvendados e transvalorados (ou os transmuta) pelo humano em novas avaliações.

A particularidade nesse processo está na incompatibilidade entre fatos e interpretações. Isso porque, para Granier (2009), a interpretação é tão caótica quanto o próprio mundo, o que impede qualquer ontologia ou correspondência fiel entre Ser, ou coisa-em-si e avaliação, essência e palavra. Não há interpretação única e exata para Granier, pois mundo e valor correspondem a uma multiplicidade caótica e mutante marcada pela diferença interminável e incontornável.

Por fim, cabe trazer a contribuição de Stegmaier (2013) para pensar o topos poético como ato de verdade. Para Stegmaier, Nietzsche, assim como Heidegger, resgatou da filosofia de Aristóteles o entendimento sobre a verdade como Alethéa, ou seja, não como algo posto, dado, preestabelecido, mas como algo a ser edificado, mediante um ato de criação, como arte, poesia que surge da contiguidade entre homem e realidade. Tal herança também repercutiria na geograficidade de Dardel (2011) que por sua vez entendia a geografia como um ato poético de interpretação da terra. A diferença para com Aristóteles é que a criação da verdade parte da razão como princípio de incondicionalidade, que se faz atuante, cindida e hierarquizada tanto como sujeito (consciência) do conhecimento, quanto como objeto (substância) a ser conhecido.

No olhar de Stegmaier (2013), Nietzsche trata a contiguidade no ato poético de veracidade de maneira muito diferente. Não há cisão, ou hierarquia entre sujeito e objeto, pois não há substância ou imperativo racional que comande ou determine o pensamento ou a criação da verdade. Na perspectiva de Nietzsche (2012b, 2014), não há nem sequer sujeito e objeto, o que há é a própria terra, uma unidade entre corpos compondo a efetividade do mundo. $\bigcirc$ humano, como parte dessa contiguidade corpórea é só um nervo que salta desta relação, evidenciando um gesto que expressa, em sua particularidade, aquilo que acontece a cada instante. Em outras palavras, o homem é a parte do todo que expressa a vida e a terra em belas palavras, na poesia que evidencia a verdade dos acontecimentos.

Todavia, a verdade para Nietzsche não corresponde à verdade ao sabor da tradição: cristalizada, universal, absoluta e inquestionável. Segundo Stegmaier (2013), o transvalorar sobre a verdade em Nietzsche se dá pelo verdadeiro, ou seja, a verdade transitória, inconclusa, plural, em perspectiva e a se fazer, que acontece em circunstância e que se abre, ininterruptamente, a multiplicidade de interpretações, a uma infinidade de visadas, uma verdade que conta sempre com uma margem de manobra de pontos de vista. Deste modo, o ato de criação poética de Nietzsche sobre o verdadeiro é interminável, um esforço que não cessa, o que corresponde a uma postura genuinamente científica.

\section{Terra como horizonte humano}

Em seus estudos, o filósofo estadunidense Gary Shapiro $(2010,2013)$ trouxe uma interessante reflexão sobre a terra em Nietzsche, perspectiva que oscila entre duas órbitas em íntima relação: (1) terra como acontecimento, o que, de certo modo, nos remete, mais uma vez, 
à terceira visão sobre a terra como subtaneidade (circunstancialidade percebida), e (2) terra como jardim do humano, isto é, como horizonte de possibilidades e criação (arte) que emerge dos acontecimentos.

Para elucidar a primeira órbita terrestre (terra como acontecimento), Shapiro (2013) explora um interessante embate entre Nietzsche e Hegel sobre o sentido histórico. Para o estudioso, Nietzsche sustenta uma postura combativa diante da centralidade histórica hegeliana em torno da figura do Estado. Na visão de Hegel, grupos humanos desprovidos de Estado não têm História, sendo esta atribuída ao domínio da linguagem sobre os fatos e acontecimentos, o que possibilita a fundação de discursos sobre o passado, presente e o futuro de um povo ou nação. Por esta perspectiva hegeliana funda-se a ideia de mundo como discurso histórico sobre a trajetória de um Estado, resultando na seguinte determinação: povos sem Estado são desprovidos de História e consequentemente desprovidos de um mundo.

Tal perspectiva linear e progressiva da História é posta em xeque por Nietzsche (2009a, 2012b) por uma preocupação de cunho essencialmente geográfico, a saber, a centralidade da História em torno do Estado é uma farsa idealista, uma intencionalidade moral, sendo o instante de acontecimento o solo (base-terra) originário para a História. A cada acontecimento, assim como em cada contexto cultural, passado e futuro são revisitados e reorientados em suas interpretações e escrita, o que nos faz pensar que as dimensões do tempo não passam de abstrações que acompanham o próprio acontecimento, portanto, uma leitura que funde passado, presente e futuro em um só instante. A centralidade histórica trata-se, na visão de Shapiro (2010, 2013), de uma interpretação geográfica em que a terra, como acontecimento, é sempre pré-histórica, pré-discursiva e pré-moral. Não se pode contar com predeterminações interpretativas sobre a realidade, pois esta sempre se apresenta como outra a cada momento. Todavia, isso não significa que o discurso ou a linguagem nunca será posta junto e sobre a terra. Sobre esse problema é que compete pensar a segunda orbita nietzschiana sobre a terra, pensada por Gary Shapiro (2103): terra como jardim do homem, terra-moral ou horizonte de possibilidades.

Sobre o sentido de jardim, Shapiro (2013) lançou interpretações inspiradas na geografia e na geologia. Entre a mais central delas é a ideia de jardim como antropoceno, período geológico em que as estratigrafias da terra estão profundamente marcadas pela ação do humano, colocando-o como um dos agentes expressivos de transformações decisivas e irreversíveis sobre a physis. Desse modo, a terra, como acontecimento e condição pré-moral, deve ter seus estratos interpretados pelo homem para que este dê à terra uma direção, lançando sobre ela novos significados e sentidos, ou seja, fazendo da terra pré-moral, a terra humana (terra-moral), o jardim de felicidade (garden-happiness) ou a felicidade edênica da terra que deve ser preparada, cultivada para a chegada do além-do-homem.

Para Heidegger (2010), o niilismo europeu, que, por sua vez, levou as Ciências, assim como a Filosofia moderna, a manifestarem os sintomas de sua crise derradeira, o acontecimento apropriativo fundamental que deu a Nietzsche (2009a, 2011b) aquilo digno de ser pensado em sua obra, a saber: a transvaloração de todos os valores, isto é, a necessidade de se criar novos valores, nomes, palavras em fidelidade à terra, propor sobre ela e a partir dela uma nova moral, motivação que nos resgata a quarta visão sobre terra como topos poético. 
A terra humana de Shapiro (2013) é justamente o resultado desse topos poético, é a terra tingida de tons, cores, sentidos e significados que a faz terreno fértil para edificar o jardim de felicidades, a abertura para um mundo como horizonte para a vida humana. Nesse sentido, o ato de cultivar jardins e fundar mundos é entendido por Shapiro como uma arquitetura da paisagem, um erigir diretamente sobre a terra, que se vale de uma geoestética que, por sua vez, brota de uma geofilosofia.

Já na Geografia de Dardel (2011) a terra nietzschiana como jardim humano poderia ser associada ao que o geógrafo entende por realidade geográfica ou mesmo espaço geográfico. Para o autor, a dimensão geográfica é antropogênica, ou seja, a terra para o homem, apreendida, compreendida e decifrada pela sensibilidade e pensamento humano. Ao se fazer geográfica, a Terra passa a ser possibilidade para a ação humana, não só via linguagem, mas sobretudo vima espaço construído, que faz dela não só habitat propício ao desdobramento da sociedade, mas seu projeto mais incisivo.

Tal perspectiva não se encontra somente em Dardel, que pelo discorrido acabou nos revelando não só um uso mais frequente do termo "terra" em sua geografia, como também relativas compatibilidades em todas as cinco visões sobre a terra em Nietzsche. Terra como possibilidades para o humano também é possível ser conferida na proposta de Réclus, que se diferencia de Dardel por dar peso secundário e menor à natureza no processo de formação do espaço ou meio geográfico. Já para Dardel, a força da terra é tão determinante sobre a realidade quanto o poder construtivo da liberdade humana.

\section{A matryoshka sem núcleo}

As cinco visões sobre terra aqui discorridas podem ser vistas como diferença, marca da filosofia nietzschiana na leitura de Deleuze (1976). Para este, a diferença está justamente na multiplicidade de sentidos propostos pelo pensamento, como também pelo gênero de proposição filosófica e interpretativa desse pensador. As metáforas contidas em seus aforismos e poemas trazem consigo a afirmação da pluralidade de sentidos na unidade de suas anunciações. Desta feita, trazemos em nossa proposta sobre a terra uma leitura, assim como atitude própria para com o sentido de diferença, a saber, um esforço de nomeação múltipla, que realça a pluralidade de noções, palavras, sentenças que se encontram em transição e em relação no mesmo enunciado, no lugar de uma impossibilidade, falta total de sentido, ou uma relutância inflexível a todo e qualquer esforço de nomeação.

Cabe salientar que a nomeação múltipla sobre os sentidos de terra não se configura como um empreendimento decisivo e categórico, pois está em devir, em um vir-a-ser, assim como o caos característico da própria terra e do cosmo. Trata-se, portanto, de um empreendimento poético (poíesis - fazer), interpretativo, criativo, com aberturas ao conceitual, de cunho geográfico, cuja multiplicidade se limita apenas pela circunstância da experiência e da situação do pensar, o que nos leva a afirmar a possibilidade ilimitada de novas, múltiplas e intermináveis nomeações futuras do mesmo fenômeno. Sendo assim, se há alguma analogia de rasura ou rizoma em nossa nomeação perspectivista, ela se dá pela afirmação plural de sentidos, ao invés de uma negação reativa de que há qualquer sentido. 
Essa terra nietzschiana, portanto, está posta diante de uma espécie de prisma que estende a palavra radical (terra) a sentidos diversos e que, à primeira vista, se complementam (terra-mundo-aquém; terra-cosmo; terra-subtaneidade; terra-topos-poético; terra-horizonte-humano). Cada um deles nos revela uma perspectiva sobre a terra dependendo de onde se está na situação do pensar sobre.

Todavia, mesmo que esses sentidos pareçam, à primeira vista, se complementar e encaixar muito bem em nossos argumentos, é de se destacar suas latentes contradições, o que na leitura de Müller-Lauter (2009) colocaria a nossa interpretação em sintonia com o antagonismo característico da filosofia de Nietzsche (2011a).

Na tentativa de abrir trilhas para pensar essa multiplicidade contraditória-harmoniosa das visões sobre a terra, cabe o esforço de uma imagem: para nós, as cinco visões terrenas em Nietzsche constituem uma espécie de matryoshka. Por serem ocas, as matryoshkas guardam-se umas às outras, com exceção da menor, a única que cumpre o papel de núcleo maciço, a única a ser acolhida por todas sem, no entanto, acolher nenhuma réplica dentro de si.

Para não ser tão simplista em nossa metáfora, a terra nietzschiana, como nossa matryoshka, não teria um núcleo irredutível e impenetrável. Todas as suas dobras seriam ocas, e todas acolheriam umas às outras igualmente, mesmo havendo entre elas contradições. Entre as dobras, também não haveria nenhuma ordem, da menor para a maior, o que possibilitaria montá-la a partir de qualquer um de seus constituintes, basta escolher, ou melhor, cabem as escolhas de cada circunstância do pensamento.

$\bigcirc$ pequeno grande livro de Dardel mostra, mais uma vez, sua inestimável contribuição à geografia. Não porque tenha erigido um grande corpus ou mesmo um edifício amplo para ser ocupado. Antes, o valor dessa obra está justamente na sua capacidade polissêmica de, a partir de uma perspectiva fenomenológica e filosófica da geografia, ao mesmo tempo, abrir possibilidade de abrigá-las em sua multiplicidade. A reverberação das cinco visões em suas páginas reitera seu papel heurístico de possibilitar caminhos para a geografia como um todo.

A nosso ver, as cinco visões tratadas nos dão terreno para, em breve, problematizar e continuar rediscutindo conceitos fundamentais da geografia. Permite, sobretudo, contribuir para retomar a reflexão sobre o sentido fundante da terra para o geográfico, seja na investigação de seus fundamentos ao longo da história da disciplina (apenas pontuados aqui, no início deste texto), seja nas possibilidades que a proposta geofilosófica abre como possibilidade de uma filosofia da geografia.

As cinco visões não necessariamente fundam novas geografias, mas talvez permitam novas conexões entre as várias perspectivas. Elas perpassam o pensamento geográfico e o esforço contemporâneo de pluralidade da disciplina. Em vista disso, sua potência criativa está no "e", não no "ou".

A terra, em sua multiplicidade, nos traz não apenas seus sentidos e devires como frutíferas proposições geofilosóficas, ou protoconceitos para se pensar o geográfico, como também um indicativo epistêmico e metodológico a partir do perspectivismo nietzschiano. Sua força anunciativa nos provoca a pensar as categorias geográficas e os fenômenos correspondentes não como fatias ou peças de uma fragmentação mecânica, sistemática e irrecuperável, mas como dimensões de um mesmo, faces de uma unidade, perspectivas de um todo indissociado. Seu desafio se revela algo interessante de se pensar, talvez um caminho distinto a seguir e compartilhar. 


\section{Referências}

ANDRADE, M. C. A terra e o homem no Nordeste. São Paulo: Brasiliense, 1963.

ASTOR, D. Nietzsche. Trad. Gustavo A. Feix. Porto Alegre: LEPM, 2013.

AZEVEDO, A. (Org.) . Brasil: a terra e o homem. São Paulo: Cia. Ed. Nacional, 1967. 2v.

BACHELARD, G. O ar e os sonhos: ensaio sobre a imaginação do movimento. Trad. Paulo Neves. São Paulo: WMF Martins Fontes, 2001.

BARRENECHEA, M. A. Nietzsche e o corpo. Rio de Janeiro: 7Letras, 2009.

BERDOULAY, $V$. A escola francesa de geografia: uma abordagem contextual. Trad. Oswaldo Bueno Amorim Filho. São Paulo: Perspectiva, 2017.

BERQUE, A. Poétique de la terre: histoire naturelle et histoire humaine, essai de mésologie. Paris: Belin, 2014.

BERQUE, A. Écumène: introduction à l'étude des millieux humains. Paris: Belin, 2009.

BESSE, J.-M. Ver a terra: seis ensaios sobre a paisagem e a geografia. Trad. Vladimir Bartalini. São Paulo: Perspetiva, 2006.

BUTTIMER, A. Society and milieu in the French geographic tradition. Washington: AAG, 1971.

CLAVAL, P. Terra dos homens: a Geografia. São Paulo: Contexto, 2010.

DARDEL, E. O Homem e a Terra: natureza da realidade geográfica. Trad. Werther Holzer. São Paulo: Perspectiva, 2011.

DAVIM. D. E. M. As forças em luta: segredos entre Nietzsche, Bachelard e Dardel sobre as vontades da terra. In: ENCONTRO NACIONAL DE PÓS-GRADUAÇÃO EM GEOGRAFIA, 9, 2015, Presidente Prudente. Anais... Presidente Prudente: UFGD, 2015. Disponível em: http://www.enanpege.ggf.br/2015/anais/arquivos/17/499.pdf. Acesso em: 2 jun. 2015.

DELEUZE, G. Nietzsche e a filosofia. Trad. Ruth Jofilly Dias e Edmundo Fernandes Dias. Rio de Janeiro: Ed. Rio de janeiro, 1976.

D'IORIO, P. Nietzsche na Itália: a viagem que mudou os rumos da filosofia. Trad. Joana Angélica d'Avila Melo. Rio de Janeiro: Zahar, 2014.

FEITOSA, C. Filosofia e Geografia em Nietzsche. In: BARRENECHEA, M. A.; FEITOSA, C.; PINHEIRO, P.; SUAREZ, R. (Org.). Nietzsche e as ciências. Rio de Janeiro: 7letras, 2011. p. 139-149.

FOGEL, G. Corpo como realidade imediata. In: BARRENECHEA, M. A.; FEITOSA, C.; PINHEIRO, P.; SUAREZ, R. (Org.). Nietzsche e as ciências. Rio de Janeiro: 7letras, 2011. p. 81-85.

GIACÓIA JR., O. Nietzsche. São Paulo: Publifolha, 2000.

GRANIER, J. Nietzsche. Trad. Denise Bootmann. Porto Alegre: LEPM, 2009. 
GROS, F. Caminhar, uma filosofia. Trad. Lília Ledon da Silva. São Paulo: É Realizações, 2010.

GÜNZEL, S. Nietzsche's Geophilosophy. Journal of Nietzsche Studies, New York, v. 25, n. 1, p. 78-91, 2003.

HAGGETT, P. Geography: a modern synthesis. 2nd ed. New York: Harper, 1975.

HARVEY, D. Social justice and the city. Baltimore: John Hopkins, 1973.

HARVEY, D. Explanation in geography. New York: St. Martin's, 1969.

HEIDEGGER, M. Nietzsche (1). Trad. Marco Antônio Casanova. Rio de Janeiro: Forense Universitária, 2010.

HEIDEGGER, M. Sobre o humanismo. Trad. Emmanuel Carneiro Leão. Rio de Janeiro: Tempo Brasileiro, 2009.

HOLZER, W. Mundo e lugar: ensaio de geografia fenomenológica. MARANDOLA JR., E.; HOLZER, W.; OLIVEIRA, L. (Org.) Qual o espaço do lugar? Geografia, epistemologia, fenomenologia. São Paulo: Perspectiva, 2012. p. 281-304.

HUMBOLDT, A. Cosmos: essai d'une description physique du monde. Trad. H. Faye. Paris: Gide, 1859.

KINGSBURY, P. Editorial Introduction: Friedrich Nietzsche and Geography. ACME - An International E-Journal for Critical Geographies, Okanagan, CA, v. 9, n. 1, p. $1-9,2010 a$.

KINGSBURY, P. Unearthing Nietzsche's Bomb: Nuance, Explosiveness, Aesthetics. ACME

- An International E-Journal for Critical Geographies, Okanagan, CA, v. 9 , n. 1, p. 48-61, 2010b.

KOURETAS, D. The Oracle of Trophonius: A Kind of Shock Treatment Associated with Sensory Deprivation in Ancient Greece. The British Journal of Psychiatry. London, v. 505, n. 113, p. 1441-1446, 1967.

MACHADO, R. O nascimento do trágico: de Schiller a Nietzsche. Rio de Janeiro: Jorge Zahar, 2006.

MALPAS, J. Heidegger's topology: being, place, world. Cambridge: MIT Press, 2008.

MARTON, S. Da biologia a física: vontade de potencia e eterno retorno do mesmo. Nietzsche e as ciências da Natureza. In: BARRENECHEA, M. A.; FEITOSA, C.; PINHEIRO, P.; SUAREZ, R. (Org.). Nietzsche e as ciências. Rio de Janeiro: 7letras, 2011. p. $114-129$.

MARTON, S. Nietzsche: das forças cósmicas aos valores humanos. Belo Horizonte: UFMG, 2010.

MÜLLER-LAUTER, W. Nietzsche: sua filosofia dos antagonismos e os antagonismos de sua filosofia. Trad. Claudemir Araldi. São Paulo: Unifesp, 2009. 
NIETZSCHE, F. O anticristo: ensaio de uma critica ao cristianismo. In: NIETZSCHE, Friedrich. $\mathbf{O}$ anticristo e ditirambos de Dionísio. Trad. Paulo César de Souza. São Paulo: Companhia das Letras, 2016.

NIETZSCHE, F. Além do bem e do mal: prelúdio de uma filosofia do futuro. Tradução de Paulo César de Souza. São Paulo: Companhia das Letras, 2014.

NIETZSCHE, F. Fragmentos póstumos 1887-1889. Trad. Marco Antônio Casanova. Rio de Janeiro: Forense Universitária, 2012a.

NIETZSCHE, F. Humano demasiado humano: um livro para espíritos livres. Trad. Paulo César de Souza. São Paulo: Companhia das Letras, 2012b. v. 1.

NIETZSCHE, F. A gaia ciência. Trad. Paulo César de Souza. São Paulo: Companhia das Letras, 2011 a.

NIETZSCHE, F. Assim falou Zaratustra: um livro para todos e para ninguém. Trad. Paulo César de Souza. São Paulo: Companhia das Letras, $2011 \mathrm{~b}$.

NIETZSCHE, F. Genealogia da moral: uma polêmica. Trad. Paulo César de Souza. São Paulo: Companhia das Letras, 2009a.

NIETZSCHE, F. Crepúsculo dos ídolos: como se filosofa com o martelo. Trad. Renato Zwick. Porto Alegre: LEPM, 2009b.

NIETZSCHE, F. Humano demasiado humano: um livro para espíritos livres. Trad. Paulo César de Souza. São Paulo: Companhia das Letras, 2008. v. 2.

NIETZSCHE, F. Aurora: reflexões sobre os preconceitos morais. Trad. Paulo César de Souza. São Paulo. Companhia das Letras, 2004.

NIETZSCHE, F. O eterno retorno: a vontade de potência. In: Os Pensadores - Nietzsche: obras incompletas. Trad. Rubens Rodrigues Torres Filho. São Paulo: Abril Cultural, 1884-1888/1999. p. 443-450.

NIETZSCHE, F. O nascimento do trágico: helenismo e pessimismo. Trad. J. Guinsburg. São Paulo: Companhia das Letras, 1992.

OLIVER, J. E. Physical geography: principles and applications. North Scituate, RI: Duxbury, 1979.

PARKES, G. Nietzsche's environmental philosophy: a trans-european perspective. Environmental Ethics, Albuquerque, NM, v.1, n. 27, p. 77-91, 2005.

PATTISON, W. As quatro tradições da geografia. Boletim de Geografia Teorética, Rio Claro, v. 7, n. 13, p. 101-110, 1977.

RANDLES, W. G. L. The Unmaking of the Medieval Christian Cosmos, 15001760: From Solid Heavens to Boundless Aether. Aldershot, England, and Brookfield: Ashgate Publishing, 1999.

RÉCLUS, E. A natureza da geografia. In: ANDRADE, M. C. (Org.). Élisée Réclus. São Paulo: Ática, 1985. (Coleção Grandes Cientistas Sociais). 
RÉCLUS, E. L'homme et la terre. Paris: L. Universelle, 1905.

SAINT-EXUPÉRY, A. Terra dos homens. Rio de Janeiro: Nova Fronteira, 2006.

SANTOS, M. Por uma geografia nova: da crítica da geografia a uma geografia crítica. São Paulo: Hucitec, 1978.

SHAPIRO, G. Earth's Garden-Happiness: Nietzsche's Geoaesthetics of the Anthropocene. Nietzsche Studien, v. 42, n. 1, p. 67-84, Nov. 2013.

SHAPIRO, G. A crise de Nietzsche: dívida, globalização e "grandes acontecimentos". In: PESSOA, F; BARBOSA, R. Do abismo às montanhas. Rio de Janeiro: Museu Vale, 2010. p. 22-40.

SILVEIRA, R. W. D.; VITTE, A. C. Os quadros linguísticos da paisagem em Alexander von Humboldt: correspondência com o meium-de-reflexão do romantistmo alemão de início do século XIX. Floema, ano VI, n. 6, p. 153-173, 2010.

STEGMAIER, W. As linhas fundamentais do pensamento de Nietzsche: coletânea de artigos. Trad. Oswaldo Giacoia Jr. et al. Petrópolis, RJ: Vozes, 2013.

VITTE, A. C.; SILVEIRA, R. W. D. Natureza em Alexander von Humboldt: entre a ontologia e o empirismo. Mercator, v. 9, n. 20, p. 179-195, 2010.

WAINWRIGHT, J. Nietzsche Contra the Real World. ACME - An International E-Journal for Critical Geographies, Okanagan, CA, v. 9, n. 1, p. 21-33, 2010. 